\title{
The Impact of Contraceptive Counseling in Primary Care on Contraceptive Use
}

\author{
Jessica K. Lee, $S B^{7}$, Sara M. Parisi, MS, MPH ${ }^{2}$, Aletha Y. Akers, MD, MPH ${ }^{1,4}$, \\ Sonya Borrerro, $M D, M S^{1,2}$, and Eleanor Bimla Schwarz, MD, $M S^{1,2,3,4}$ \\ ${ }^{1}$ University of Pittsburgh School of Medicine, Pittsburgh, PA, USA; ${ }^{2}$ Department of Medicine University of Pittsburgh, Pittsburgh, PA, USA; \\ ${ }^{3}$ Department of Epidemiology University of Pittsburgh, Pittsburgh, PA, USA; ${ }^{4}$ Department of Obstetrics, Gynecology, and Reproductive \\ Sciences University of Pittsburgh, Pittsburgh, PA, USA.
}

BACKGROUND: Whether contraceptive counseling improves contraceptive use is unknown.

OBJECTIVE: To evaluate the association between contraceptive counseling provided by primary care physicians and patients' contraceptive use.

DESIGN/PARTICIPANTS: All women aged 18-50 who visited one of four primary care clinics between October 2008 and April 2010 were invited to complete surveys about their visit. Seven to 30 days post visit, participants completed a survey assessing pregnancy intentions, receipt of contraceptive counseling, and use of contraception at last sexual intercourse. Survey data were linked to medical record data regarding contraceptive prescriptions prior to and during the clinic visit. Women were classified as in need of contraceptive counseling if they were sexually active, were not pregnant or trying to get pregnant, and had no evidence of contraceptive use prior to their index clinic visit.

KEY RESULTS: Fifty percent ( $n=386)$ of women were in need of contraceptive counseling at the time of their visit. Those who received contraceptive counseling from a primary care provider were more likely to report use of hormonal contraception when they last had sex (unadjusted OR: 3.83, CI: 2.25-6.52), even after adjusting for age, race, education, income, marital status, pregnancy intentions, and prior pregnancy (adjusted OR: 2.68, CI: 1.48-4.87). Counseling regarding specific types of contraception was associated with an increased use of those methods. For example, counseling regarding hormonal contraceptives was associated with a greater likelihood of use of hormonal methods (adjusted OR: 4.78, CI: 2.519.12) and counseling regarding highly effective reversible methods was highly associated with use of those methods (adjusted OR: 18.45, CI: 4.88-69.84). These same relationships were observed for women with prior evidence of contraceptive use.

CONCLUSIONS: Contraceptive counseling in primary care settings is associated with increased hormonal contraceptive use at last intercourse. Increasing provision of contraceptive counseling in primary care may reduce unintended pregnancy.

KEY WORDS: contraceptive counseling; contraception; primary care; women's health.

J Gen Intern Med 26(7):731-6

Published online February 8, 2011
DOI: $10.1007 / \mathrm{s} 11606-011-1647-3$

(C) Society of General Internal Medicine 2011

\section{INTRODUCTION}

Despite the array of contraceptive options available in the United States, unplanned pregnancies continue to occur. In 2002 , an estimated $49 \%$ of US pregnancies (3.1 million) were unplanned, ${ }^{1}$ resulting in 1.3 million induced abortions, 1.4 million unintended births ${ }^{1}$, and significant societal costs ${ }^{2-4}$. While the majority of unplanned pregnancies in the US occurred to women who were not using any method of contraception in the month they conceived ${ }^{1,5}$, more than $40 \%$ of women with unplanned pregnancies conceived after using contraception inconsistently or incorrectly ${ }^{1}$.

Poor contraceptive use has been attributed to a variety of factors, including contraceptive cost, method-related difficulties, and cultural norms ${ }^{5}$. Communication between clinicians and patients about contraception has also been identified as a potentially important factor in promoting effective contraceptive use ${ }^{6}$. However, the impact of contraceptive counseling on contraceptive use has not been adequately explored.

According to the U.S. Preventive Services Task Force (USPSTF), the goal of clinician counseling is to change health behaviors and improve health status by increasing patients' knowledge and confidence in their ability to affect their health. While the 1996 USPSTF's highly-regarded Guide to Clinical Preventive Services recommended "provision of periodic counseling about effective contraceptive methods for all persons at risk of unintended pregnancy," this recommendation was later withdrawn due to "insufficient evidence supporting the efficacy of contraceptive counseling in changing contraceptive behavior and improving health outcomes ${ }^{7}$." Similarly, the related Preventive Services for Adults, classifies preconception and pregnancy prevention counseling as "Preventive Services for Which the Evidence is Currently Incomplete and/or High Burden and Low Cost, Therefore Left to the Judgment of Individual Medical Groups, Clinicians and Their Patients (Level III) ${ }^{8}$."

A 2003 review conducted by Moos et al. examined 74 articles and concluded that virtually no experimental or observational literature reliably answered questions about the effectiveness of counseling in the clinical setting to reduce rates of unintended pregnancies ${ }^{9}$. Furthermore, few articles specifically address the 
relationship between counseling and contraceptive initiation or continued use ${ }^{10}$. Recent data from the National Survey of Family growth showed that women who received contraceptive counseling in the past year had an $80 \%$ decreased risk of contraception non-use ${ }^{11}$. Another study found that female university students who reported that a healthcare worker had ever talked to them about contraception had over six times the odds of being current contraception users ${ }^{12}$. Harper et al. found that women's reports of provider counseling were significantly associated with the initiation of a contraceptive method initiated after the clinic visit ${ }^{13}$.

The purpose of this study is to provide more insight into the relationship between contraceptive counseling provided in primary care settings and patients' contraceptive use. We focus on the primary care setting because it is the principal source of health care for many women ${ }^{14}$, and contraceptive counseling provided in this setting has received little prior study. Specifically, we assessed whether receipt of contraceptive counseling at the most recent visit to a primary care clinic is associated with greater likelihood of self-reported contraception use at last sexual intercourse. We also evaluated whether the content and quality of contraceptive counseling influenced the type of contraception used at last intercourse.

\section{METHODS}

\section{Data Collection}

All women aged 18-50 years who visited one of four primary care clinics in western Pennsylvania between October 2008 and April 2010 were invited to complete a follow-up survey 7-30 days after the index visit as part of a larger study evaluating the use of clinical decision support. These clinics included three community-based family practice clinics, and one academic general internal medicine clinic; all provide care to publicly and privately insured patients. Participants provided signed informed consent and received instructions on how to access the survey at the time of their clinic visit. Women could complete the survey online or by phone. Participants who completed the survey received a $\$ 10$ gift card. Participants were also asked for permission to review their electronic medical record (EMR) data. This study was approved by the University of Pittsburgh Institutional Review Board.

\section{Survey}

The 75-question survey assessed patient characteristics (i.e., age, education, race, marital status, household income, insurance status, medical assistance status, perceived overall health status, religiosity, personal objections to contraception and/or abortion, pregnancy intention, and number of prior pregnancies, live births, abortions, and miscarriages). Pregnancy intention was measured using a previously validated single question with five response categories ${ }^{15}$. Women were asked whether they received contraceptive counseling at the index visit. The content of contraceptive counseling was assessed by asking what types of contraception were dis- cussed. The quality of the contraceptive counseling was assessed with two items. One asked participants to rank their satisfaction with the contraceptive counseling received using four response options that ranged from very satisfied to not satisfied. Responses were dichotomized into "Satisfied/Very satisfied" or "Somewhat satisfied/Not satisfied". The second item asked whether the clinician answered all the participant's questions about birth control. Participants were also asked to specify which methods of contraception they used when they last had intercourse, and which they had used in the past 3 months. When considering contraceptive use at last intercourse, we examined (1) use of any reversible contraceptive method (condom, diaphragm, oral contraceptive, contraceptive patch, ring, injection, implant, or intrauterine contraceptive (IUD)), (2) use of hormonal methods (pills (OCPs), patch, ring, or injection) or (3) use of highly effective reversible methods (IUD or implant). However, participants were not specifically questioned about the date they last had intercourse. Finally, participants were asked to report how often they engaged in unprotected sex in the past 3 months using a five-point Likert scale ("Always had unprotected sex" to "Never had unprotected sex").

\section{Electronic Medical Record Data}

We abstracted EMR data for participants from each clinic visit made during the study period. We also abstracted de-identified EMR data for non-participating women aged 18-50 years who visited the study clinics during the same time period to compare survey completers to noncompleters. Charts were reviewed to assess: the number of previous visits to the clinic; valid contraception prescriptions at the time of index visit (new or existing prescriptions that had not expired); presence of an IUD, contraceptive implant, or history of surgical sterilization; or procedure orders for a contraceptive implant (IUD, Implanon, Depo Provera injections).

\section{Statistical Analysis}

We calculated the survey response rate. We excluded women who did not need contraception (i.e., those who were trying to get pregnant, were currently pregnant, had prior surgical sterilization, had a partner with vasectomy, had never had sex with a man, or had not had sex with a man in the past 3 months). We also excluded women whose survey and EMR data could not be linked. We looked at women's history of contraceptive use prior to their clinic visit in the EMR data and divided participants into two groups: those "In need of contraceptive counseling" (no EMR evidence of contraceptive use), or "In less need of contraceptive counseling," (prior EMR evidence of contraception). Because EMR data do not capture contraception purchased over the counter or prescribed outside of the medical center, we expected discrepancies between the EMR data and women's survey responses. To reduce misclassification, women who reported consistent use of contraception in the last 3 months or never having had unprotected sex were classified as having "less need for contraceptive counseling," even if their EMR had no evidence of contraceptive use. Using chi-square testing, we compared the characteristics of those who did and did not receive 
contraceptive counseling, and those who were in need of contraceptive counseling and those with potentially less need. We examined whether women were more likely to receive contraceptive counseling from a physician they considered their primary care provider. We also explored rates of receipt of contraceptive prescriptions at the clinic visit between the groups who received contraceptive counseling and did not receive counseling, as well as rates of use of contraception at last intercourse by receipt of a prescription, using chi-square tests. Finally, we used multivariate logistic regression to examine the relationship between contraceptive use at last intercourse and three types of predictor variables: 1) receipt of any contraceptive counseling 2) receipt of contraceptive counseling regarding specific types of methods and 3) quality of contraceptive counseling. For each set of outcomes and predictors, we controlled for demographics, socioeconomic status and reproductive characteristics. Women who "did not report pregnancy intentions" were considered as an additional category in all analyses of this variable. For the remaining missing covariate data, we used multiple imputation by chained equations. STATA's "ice" command generated five imputed datasets, and the "mim" command was used to generate pooled OR's. We ran all models stratified by "need of contraceptive counseling." All analyses were conducted using Stata 10.0 (StataCorp. College Station, TX).

\section{RESULTS}

A total of 1,965 (19\%) eligible women visited the primary care clinics and completed surveys. On average, women completed surveys 9.5(+/-6.2) days [median (IQR): 7(5)] after visiting a study clinic (range $=5-30$ days). Women who did and did not complete surveys were of similar age (34.6 vs. 35.2 years) and marital status (51\% vs. $48 \%$ married or living with partner). However, women who completed surveys were more likely to be white $(91 \%$ vs. $81 \%, \mathrm{p}<0.001)$ and have more than a high school education $(78 \%$ vs. $71 \%, p=0.006)$. Women who completed surveys were also more likely to be established patients at the clinic ( $87 \%$ vs. $76 \%, \mathrm{p}<0.001)$. We excluded 1017 women from subsequent analyses because they were not in need of contraception. Specifically, those without need for contraception included 72 women who were trying to get pregnant or thought they were pregnant, 288 women who were surgically sterilized or had a partner with a vasectomy, 382 women who had not had sex with a man in the past 3 months or had never had sex with a man, and 275 who responded "not applicable" when asked if they had received contraception counseling. An additional 32 women were excluded as information regarding contraceptive counseling or contraception used at last intercourse was missing. Of the remaining 916 surveys, we were able to link $90.4 \%$ (828) to the EMR data. Upon linking, we eliminated an additional 58 women with EMR indication of sterilization who had not indicated sterilization on their survey, leaving us with a final sample of 770 women for this analysis.

On average, women had made 10.5(+/-12.3) [median (IQR): $7(13)]$ previous visits to the study clinics, and $75 \%$ were visiting a doctor they considered their primary care physician
(PCP) on the index visit. Overall, 37.1\% (N=286) of respondents reported receiving contraceptive counseling at their visit (Table 1). Compared to women who did not receive contraceptive counseling, those who received counseling were younger, less likely to be married or living with a partner, more likely to have previously been pregnant, given birth, or be trying to avoid pregnancy. In addition, women who received contraceptive counseling were more likely to be seeing a doctor they considered their PCP (adjusted OR: 1.79, 95\% CI: 1.24-2.57). Most women who received counseling (94.0\%) reported that all of their questions about birth control had been answered and 92.3\% were satisfied with the counseling they received.

Fifty percent $(n=386)$ of participants were categorized as "in need of contraceptive counseling" and 49.9\% ( $n=384)$ were classified as "in less need of contraceptive counseling" at the time of the study visit. Women classified as "in need" were significantly more likely to be older, married, and receiving medical assistance. They were also significantly more likely to have been pregnant, to report they currently "wouldn't mind being pregnant," to attend religious services regularly, and to have personal objections to contraceptive use and/or abortion.

Women "in need of contraceptive counseling" were significantly less likely to report having received any counseling at their clinic visit (29.3\% "in need" vs. $45.1 \%$ "in less need," p= 0.001). Among women "in need of contraceptive counseling", those who reported receiving contraceptive counseling were significantly more likely to have EMR evidence of having received a new contraceptive prescription $(32.7 \%$ vs. $2.6 \%$, p< $0.001)$. Women who received a new prescription were significantly more likely to report use of contraception at last intercourse (86.5\% vs. 57.9\%, p=0.002). However, even among women who did not receive a new contraceptive prescription, receipt of contraceptive counseling was still associated with a greater likelihood of use of contraception at last intercourse $(57.9 \%$ vs. $45.9 \%, \mathrm{p}=0.06$ ). This trend was similarly apparent for women in less need of contraceptive counseling at the time of their clinic visit. Among those women who had evidence of contraceptive use before their index visit, those who received contraceptive counseling were more likely to report contraceptive use at last intercourse, whether or not a new contraceptive prescription was provided at the index visit $(89.0 \%$ vs $82.0 \%, \mathrm{p}=0.05)$.

The majority $(68.8 \%)$ of women reported they had used a reversible method of contraception at the time of last intercourse. Specifically, $20.6 \%$ used a barrier method, $42.6 \%$ used a hormonal contraceptive, and $5.6 \%$ used a highly effective reversible method of contraception. In bivariate and adjusted models, women in need of contraceptive counseling who received counseling regarding any method were more likely to use hormonal birth control the last time they had intercourse (unadjusted OR: 3.83, CI: 2.25-6.52, adjusted OR: 2.68, CI: 1.48-4.87) (Table 2). A relationship was also observed between counseling about specific contraception methods and use of that method at last intercourse. For example, counseling regarding hormonal contraceptives was highly associated with use of hormonal methods (unadjusted OR: 6.49, CI: 3.70-11.37, adjusted OR: 4.78, CI: 2.51-9.12) and counseling regarding highly effective reversible methods was highly associated with use of those methods (unadjusted OR: 16.52, CI: 5.78-47.17, adjusted OR: 18.45, CI: 4.88-69.84). The same relationships were detected for women in less need of counseling (Table 3), but they were of a lesser magnitude. For all women, having a PCP answer all questions regarding birth control was positively 
Table 1. Sample Characteristics by Receipt of Contraceptive Counseling at Most Recent Visit to a Primary Care Clinic

\begin{tabular}{|c|c|c|c|}
\hline & $\begin{array}{l}\text { Received Any Contraceptive } \\
\text { Counseling } N=286\end{array}$ & $\begin{array}{l}\text { Did Not Receive Any Contraceptive } \\
\text { Counseling } N=484\end{array}$ & p-value \\
\hline $\begin{array}{l}\text { In need of contraceptive counseling } \\
(\mathrm{N}=770)\end{array}$ & 113 (39.5\%) & 273 (56.4\%) & $<0.001$ \\
\hline $\begin{array}{l}\text { Received a contraceptive prescription } \\
(\mathrm{N}=770)\end{array}$ & $80(28.0 \%)$ & $25(5.2 \%)$ & $<0.001$ \\
\hline Age $(N=770)$ & & & $<0.001$ \\
\hline $18-21$ & $45(15.7 \%)$ & $59(12.2 \%)$ & \\
\hline $22-30$ & $133(46.5 \%)$ & $164(33.9 \%)$ & \\
\hline $31-40$ & $84(29.4 \%)$ & $149(30.8 \%)$ & \\
\hline $41-50$ & $24(8.4 \%)$ & $112(23.1 \%)$ & \\
\hline Education $(\mathrm{N}=768)$ & & & 0.79 \\
\hline High school diploma or less & $33(11.6 \%)$ & $59(12.2 \%)$ & \\
\hline Some college or more & $252(88.4 \%)$ & $424(87.8 \%)$ & \\
\hline Marital status $(\mathrm{N}=769)$ & & & $<0.001$ \\
\hline Married or living with partner & $156(54.7 \%)$ & $321(66.3 \%)$ & \\
\hline Other & $129(45.3 \%)$ & $163(33.7 \%)$ & \\
\hline Race $(\mathrm{N}=768)$ & & & 0.71 \\
\hline White & $270(94.4 \%)$ & 455 (94.4\%) & \\
\hline Black & $8(2.8 \%)$ & $10(2.1 \%)$ & \\
\hline Other & $8(2.8 \%)$ & $17(3.5 \%)$ & \\
\hline Household Income $(\mathrm{N}=695)$ & & & 0.26 \\
\hline Less than $\$ 20,000 / y r$ & $16(6.0 \%)$ & $25(5.8 \%)$ & \\
\hline Less than $\$ 21,000-50,000 / y r$ & $102(38.4 \%)$ & 139 (32.4\%) & \\
\hline More than $\$ 50,000 / y r$ & $148(55.6 \%)$ & $265(61.8 \%)$ & \\
\hline Health insurance $(\mathrm{N}=758)$ & & & 0.59 \\
\hline No & $8(2.9 \%)$ & $17(3.6 \%)$ & \\
\hline Yes & $273(97.2 \%)$ & $460(96.4 \%)$ & \\
\hline Medical assistance $(\mathrm{N}=765)$ & & & 0.17 \\
\hline No & $249(87.4 \%)$ & $415(86.5 \%)$ & \\
\hline Yes & $22(7.7 \%)$ & $51(10.6 \%)$ & \\
\hline Don't know & $14(4.9)$ & $14(2.9 \%)$ & \\
\hline Perceived overall health status $(\mathrm{N}=770)$ & & & 0.20 \\
\hline Good- Excellent & $268(93.7 \%)$ & $441(91.1 \%)$ & \\
\hline Poor- Fair & $18(6.3 \%)$ & $43(8.9 \%)$ & \\
\hline Religiosity (N=750) & & & 0.05 \\
\hline Never attends services & $69(24.4 \%)$ & $116(24.8 \%)$ & \\
\hline Attends services $<1$ time/week & $180(63.6 \%)$ & $265(56.8 \%)$ & \\
\hline Attends services $>1$ time/week & $34(12.0 \%)$ & $86(18.4 \%)$ & \\
\hline Personal objection to contraception $(\mathrm{N}=770)$ & & & 0.74 \\
\hline No & $263(92.0 \%)$ & $438(90.5 \%)$ & \\
\hline Yes & $14(4.9 \%)$ & $30(6.2 \%)$ & \\
\hline Don’t know & $9(3.2 \%)$ & $16(3.3 \%)$ & \\
\hline Personal objection to abortion $(\mathrm{N}=770)$ & & & 0.20 \\
\hline No & $158(55.2 \%)$ & $266(55.0 \%)$ & \\
\hline Yes & $94(32.9 \%)$ & $178(36.8 \%)$ & \\
\hline Don’t know & $34(11.9 \%)$ & $40(8.3 \%)$ & \\
\hline Prior pregnancy $(\mathrm{N}=763)$ & & & $<0.001$ \\
\hline Yes & $182(64.3 \%)$ & $212(44.2 \%)$ & \\
\hline No & $101(35.7 \%)$ & $268(55.8 \%)$ & \\
\hline Prior live births* $(\mathrm{N}=363)$ & & & 0.07 \\
\hline 0 & $8(8.2 \%)$ & $19(7.2 \%)$ & \\
\hline 1 & $41(41.8 \%)$ & $79(29.8 \%)$ & \\
\hline $2+$ & $49(50.0 \%)$ & $167(63.0 \%)$ & \\
\hline Prior abortion* $(\mathrm{N}=377)$ & & & 0.79 \\
\hline 0 & $83(85.6 \%)$ & 227 (86.6\%) & \\
\hline $1+$ & $14(14.4 \%)$ & $53(13.4 \%)$ & \\
\hline Prior miscarriage* $(\mathrm{N}=362)$ & & & 0.24 \\
\hline 0 & $72(73.5 \%)$ & $177(67.1 \%)$ & \\
\hline $1+$ & $26(26.5 \%)$ & $87(33.0 \%)$ & \\
\hline Current pregnancy intentions $(\mathrm{N}=770)$ & & & 0.002 \\
\hline Trying to avoid pregnancy & $231(80.8 \%)$ & 337 (69.6\%) & \\
\hline Wouldn't mind avoiding pregnancy & $11(3.9 \%)$ & $33(6.8 \%)$ & \\
\hline Wouldn't mind pregnancy & $37(12.9 \%)$ & $72(14.9 \%)$ & \\
\hline Don't Know & $5(1.8 \%)$ & $31(6.4 \%)$ & \\
\hline Did not report intentions & $2(0.7 \%)$ & $11(2.3 \%)$ & \\
\hline
\end{tabular}

*Asked only of those women reporting a prior pregnancy 
Table 2. Association of Content and Quality of Contraceptive Counseling with Contraceptive Use at Last Intercourse Among Women in Need of Contraceptive Counseling at Time of Clinic Visit

\begin{tabular}{|c|c|c|c|c|c|c|}
\hline & \multicolumn{2}{|c|}{$\begin{array}{l}\text { Use of Any } \\
\text { Reversible Contraception }\end{array}$} & \multicolumn{2}{|l|}{$\begin{array}{l}\text { Use of Hormonal } \\
\text { Contraception }\end{array}$} & \multicolumn{2}{|c|}{$\begin{array}{l}\text { Use of Highly Effective } \\
\text { Reversible Contraception }\end{array}$} \\
\hline & $\begin{array}{l}\text { Bivariate } \\
\mathrm{N}=386\end{array}$ & $\begin{array}{l}\text { Adjusted }^{\mathrm{a}} \\
\mathrm{N}=386\end{array}$ & $\begin{array}{l}\text { Bivariate } \\
\mathrm{N}=386\end{array}$ & $\begin{array}{l}\text { Adjusted }^{\mathrm{a}} \\
\mathrm{N}=386\end{array}$ & $\begin{array}{l}\text { Bivariate } \\
\mathrm{N}=386\end{array}$ & $\begin{array}{l}\text { Adjusted }^{\mathrm{a}} \\
\mathrm{N}=219\end{array}$ \\
\hline $\begin{array}{l}\text { Discussed any reversible } \\
\text { contraceptives }\end{array}$ & $2.36(1.49-3.74)$ & $1.55(0.91-2.66)$ & $3.83(2.25-6.52)$ & $2.68(1.48-4.87)$ & $2.00(0.77-5.22)$ & $2.24(0.78-6.47)$ \\
\hline $\begin{array}{l}\text { Counseling about hormonal } \\
\text { methods }\end{array}$ & $2.24(1.34-3.77)$ & $1.25(0.67-2.36)$ & $6.49(3.70-11.37)$ & $4.78(2.51-9.12)$ & $0.21(0.03-1.62)$ & $0.22(0.03-1.78)$ \\
\hline $\begin{array}{l}\text { Counseling about highly effective } \\
\text { reversible methods }\end{array}$ & $3.05(1.19-7.80)$ & $1.85(0.67-5.09)$ & $1.77(0.71-4.14)$ & $1.19(0.44-3.21)$ & $16.52(5.78-47.17)$ & $18.45(4.88-69.84)$ \\
\hline \multirow{2}{*}{$\begin{array}{l}\text { Counseling about both hormonal } \\
\text { and highly effective }\end{array}$} & $2.04(0.69-5.99)$ & $1.02(0.31-3.36)$ & $3.65(1.31-10.16)$ & $2.15(0.70-6.56)$ & $1.38(0.17-11.1)$ & $1.80(0.19-17.22)$ \\
\hline & Bivariate $\mathrm{N}=112$ & Adjusted $^{\mathrm{a}} \mathrm{N}=105$ & Bivariate $\mathrm{N}=112$ & Adjusted $^{\mathrm{a}} \mathrm{N}=100$ & Bivariate $\mathrm{N}=\mathrm{b}$ & Adjusted $^{\mathrm{a}} \mathrm{N}=\mathrm{b}$ \\
\hline $\begin{array}{l}\text { PCP answered all questions } \\
\text { about birth control }\end{array}$ & $0.86(0.16-4.67)$ & $1.18(0.15-9.16)$ & $1.38(0.26-7.47)$ & $4.30(0.68-27.15)$ & $\mathrm{b}$ & $\mathrm{b}$ \\
\hline $\begin{array}{l}\text { Satisfied with contraceptive } \\
\text { counseling }\end{array}$ & $1.24(0.28-5.47)$ & $1.30(0.20-8.24)$ & $0.88(0.20-3.90)$ & $1.91(0.35-10.57)$ & $\mathrm{b}$ & $\mathrm{b}$ \\
\hline
\end{tabular}

${ }^{a}$ Adjusted for age, marital status, education level, race, household income, pregnancy intention, and prior pregnancy

${ }^{b}$ All women who reported use of a highly effective reversible contraceptive method reported they were satisfied with the counseling they received, precluding the use of logistic regression

associated with use of contraception at last intercourse, but the relationship was not significant.

\section{DISCUSSION}

This study of over 700 women in western Pennsylvania found that women who received contraceptive counseling from a primary care provider were significantly more likely than those who did not to subsequently report use of hormonal contraception the last time they had intercourse. These findings provide further support that contraceptive counseling by clinicians improves women's contraceptive use ${ }^{16}$ and provide evidence that PCPs can play an important role in promoting contraception use. Efforts to expand provision of contraceptive counseling in primary care settings may help reduce unintended pregnancies ${ }^{17}$.

Strengths of this study include its large sample size, the use of EMR data to determine prior evidence of contraception, and the inclusion of clinics that serve both privately and publicly insured women in both academic and community-based primary care settings. While the survey response rate was relatively low, women who completed surveys were similar to those who did not.

When interpreting these results, there are important limitations to consider. As this was a secondary analysis of data collected to evaluate clinical decision support, we were unable to determine whether participants' last intercourse occurred before or after the index clinic visit. However, prior studies indicate that the majority of women aged $18-50$ have sex at least monthly ${ }^{18,19}$. Since surveys were completed up to 30 days after women visited their primary care clinic, for most women the last episode of intercourse likely followed receipt of counseling. Our results are subject to recall bias because women were asked to provide details of counseling that occurred a week or more prior to the survey. There is the possibility that women who chose to use a contraceptive method were more likely to recall receiving counseling. There is also the chance women's need for contra-

Table 3. Association of Content and Quality of Contraceptive Counseling with Contraceptive Use at Last Intercourse Among Women in Less Need of Contraceptive Counseling at Time of Clinic Visit

\begin{tabular}{|c|c|c|c|c|c|c|}
\hline & \multicolumn{2}{|c|}{$\begin{array}{l}\text { Use of Any Reversible } \\
\text { Contraception }\end{array}$} & \multicolumn{2}{|l|}{$\begin{array}{l}\text { Use of Hormonal } \\
\text { Contraception }\end{array}$} & \multicolumn{2}{|c|}{$\begin{array}{l}\text { Use of Highly Effective } \\
\text { Reversible Contraception }\end{array}$} \\
\hline & $\begin{array}{l}\text { Bivariate } \\
\mathrm{N}=384\end{array}$ & $\begin{array}{l}\text { Adjusted }^{\mathrm{a}} \\
\mathrm{N}=384\end{array}$ & $\begin{array}{l}\text { Bivariate } \\
\mathrm{N}=384\end{array}$ & $\begin{array}{l}\text { Adjusted }^{\mathrm{a}} \\
\mathrm{N}=384\end{array}$ & $\begin{array}{l}\text { Bivariate } \\
\mathrm{N}=384\end{array}$ & $\begin{array}{l}\text { Adjusted }^{\mathrm{a}} \\
\mathrm{N}=349\end{array}$ \\
\hline Discussed any reversible contraceptives & s $1.78(0.98-3.22)$ & $1.54(0.80-2.96)$ & $1.65(1.07-2.56)$ & $1.52(0.94-2.45)$ & $0.67(0.29-1.55)$ & $0.82(0.33-2.02)$ \\
\hline Counseling about hormonal methods & $1.82(0.97-3.42)$ & $1.40(0.71-2.77)$ & $2.99(1.83-4.89)$ & $2.76(1.63-4.69)$ & $0.13(0.03-0.57)$ & $0.15(0.03-0.65)$ \\
\hline $\begin{array}{l}\text { Counseling about highly effective } \\
\text { reversible methods }\end{array}$ & $4.64(0.62-34.91)$ & $4.25(0.54-33.30)$ & $0.54(0.24-1.20)$ & $0.53(0.22-1.26)$ & $11.32(4.37-29.28)$ & $9.59(3.31-27.82)$ \\
\hline \multirow{2}{*}{$\begin{array}{l}\text { Counseling about both hormonal } \\
\text { and highly effective }\end{array}$} & $3.26(0.43-24.93)$ & ) $2.58(0.32-20.84)$ & $1.37(0.48-3.90)$ & $1.32(0.43-4.01)$ & $1.75(0.38-8.04)$ & $1.37(0.26-7.19)$ \\
\hline & Bivariate $\mathrm{N}=173$ & Adjusted $^{\mathrm{a}} \mathrm{N}=173$ & Bivariate $\mathrm{N}=173$ & Adjusted $^{\mathrm{a}} \mathrm{N}=173$ & Bivariate $\mathrm{N}=173$ & Adjusted $^{\mathrm{a}} \mathrm{N}=118$ \\
\hline $\begin{array}{l}\text { PCP answered all questions about } \\
\text { birth control }\end{array}$ & $2.15(0.42-10.9)$ & $2.99(0.51-17.53)$ & $2.98(0.82-10.80)$ & $3.69(0.89-15.33)$ & $0.46(0.05-4.13)$ & $1.32(0.09-19.50)$ \\
\hline Satisfied with contraceptive counseling & $0.63(0.07-4.88)$ & $0.31(0.02-4.28)$ & $0.74(0.20-2.76)$ & $0.47(0.10-2.35)$ & $\mathrm{b}$ & $\mathrm{b}$ \\
\hline
\end{tabular}

${ }^{a}$ Adjusted for age, marital status, education level, race, household income, pregnancy intention, and prior pregnancy

${ }^{b}$ All women who reported use of a highly effective reversible contraceptive method reported they were satisfied with the counseling they received, precluding the use of logistic regression 
ceptive counseling may have been misclassified. Some women we considered "in need of counseling" may have already been using adequate contraception prior to their survey visit. Others may have been inconsistently using the contraception documented in their EMR, as $15 \%$ of women we considered in less need of contraceptive counseling reported use of no contraception at last intercourse. By comparing the survey and EMR data when classifying women, we aimed to reduce misclassification bias. Although we controlled for several important variables that influence contraceptive use, other key covariates, such as a history of reproductive coercion, which has been negatively associated with contraceptive use ${ }^{20}$, was not assessed in this survey. Finally, there was no way to account for whether the counseling was initiated by the patient or by the physician; patients seeking contraceptive counseling who initiated such discussions with their physician would be expected to be more likely to use contraception following their visit.

Future studies are needed to assess how frequency of contraceptive counseling, length of time devoted to counseling, and number of contraceptive methods discussed affect women's subsequent contraceptive use. In addition, studies are needed that focus on the relationship between contraceptive counseling and contraceptive use among populations at high risk for unintended pregnancy. For example, studies that focus on minority and less-educated populations are needed as these women are at high risk of unintended pregnancy ${ }^{1}$ but were less likely to complete this survey. Consideration should also be given to compensating clinicians for time spent providing contraceptive counseling, as many PCPs' ability to provide contraceptive counseling is limited by time ${ }^{21}$. In a previous study, $46 \%$ of private providers and at least $21 \%$ of public providers reported that providing insurance reimbursement for time spent counseling would be a very important way to increase their provision of contraceptive counseling ${ }^{22}$.

In conclusion, we found that receipt of contraceptive counseling from a primary care provider was highly associated with reported use of hormonal contraception at last intercourse. Policy-makers, including the USPSTF, should be encouraged to support provision of contraceptive counseling in primary care settings.

Acknowledgements: The data used in this analysis were collected with funding from AHRQ R18HSO17093.

Dr. Eleanor Bimla Schwarz was funded by NICHD K23 HD051585.

\section{Conflicts of Interest: None disclosed.}

Corresponding Author: Eleanor Bimla Schwarz, MD, MS, Department of Obstetrics, Gynecology, and Reproductive Sciences University of Pittsburgh, 230 McKee Place, Suite 600, Pittsburgh, PA 15213, USA (e-mail: schwarzeb@upmc.edu).

\section{REFERENCES}

1. Finer LB, Henshaw SK. Disparities in rates of unintended pregnancy in the United States, 1994 and 2001. Perspect Sex Reprod Health. 2006;38 (2):90-96.

2. Than LC, et al. Intent to become pregnant as a predictor of exposures during pregnancy: is there a relation? J Reprod Med. 2005;50(6):389396.

3. Kost K, Landry DJ, Darroch JE. The effects of pregnancy planning status on birth outcomes and infant care. Fam Plann Perspect. 1998;30 (5):223-230

4. Trussell J, et al. Cost effectiveness of contraceptives in the United States. Contraception. 2009;79(1):5-14.

5. Frost JJ, Darroch JE, Remez L. Improving contraceptive use in the United States. Issues Brief (Alan Guttmacher Inst), 2008(1): p. 1-8.

6. Isaacs JN, Creinin MD. Miscommunication between healthcare providers and patients may result in unplanned pregnancies small star, filled. Contraception. 2003;68(5):373-376.

7. Force, U.S.P.S.T. Guide to Clinical Preventive Services. Recommendations of the U.S. Preventive Services Task Force. 3rd ed. Washington, D.C: U.S. department of Health and Human Services, Office of Public Health and Science, Office of Disease Prevention and Health Promotion. 2006.

8. Taylor D, Levi A, Simmonds $\mathbf{K}$. Reframing unintended pregnancy prevention: a public health model. Contraception. 2010;81(5):363-366.

9. Moos MK, Bartholomew NE, Lohr KN. Counseling in the clinical setting to prevent unintended pregnancy: an evidence-based research agenda. Contraception. 2003;67(2):115-132.

10. Kirby $\mathbf{D}$. The impact of programs to increase contraceptive use among adult women: a review of experimental and quasi-experimental studies. Perspect Sex Reprod Health. 2008;40(1):34-41.

11. Upson $\mathbf{K}$, et al. Factors associated with contraceptive nonuse among US women ages 35-44 years at risk of unwanted pregnancy. Contraception. 2010;81(5):427-434.

12. Huber, LR, Ersek, JL. Contraceptive use among sexually active university students. J Womens Health (Larchmt), 2009. 18(7): p. 1063-70.

13. Harper, CC, et al. Hormonal contraceptive method choice among young, low-income women: How important is the provider? Patient Educ Couns, 2010.

14. Henderson JT, Weisman CS, Grason H. Are two doctors better than one? Women's physician use and appropriate care. Womens Health Issues. 2002;12(3):138-149.

15. Kavanaugh ML, Schwarz EB. Prospective assessment of pregnancy intentions using a single- versus a multi-item measure. Perspect Sex Reprod Health. 2009;41(4):238-243.

16. Bruce J. Fundamental elements of the quality of care: a simple framework. Stud Fam Plann. 1990;21(2):61-91.

17. Barber JS, Axinn WG, Thornton A. Unwanted childbearing, health, and mother-child relationships. J Health Soc Behav. 1999;40(3):231-257.

18. Davison SL, et al. Sexual function in well women: stratification by sexual satisfaction, hormone use, and menopause status. J Sex Med. 2008;5(5): 1214-1222.

19. Addis IB, et al. Sexual activity and function in middle-aged and older women. Obstet Gynecol. 2006;107(4):755-764.

20. Miller E, et al. Reproductive coercion: connecting the dots between partner violence and unintended pregnancy. Contraception. 2010;81 (6):457-459.

21. Akers AY, et al. Providers' Perspectives on Challenges to Contraceptive Counseling in Primary Care Settings. J Womens Health (Larchmt), 2010.

22. Landry DJ, Wei J, Frost JJ. Public and private providers' involvement in improving their patients' contraceptive use. Contraception. 2008;78 (1):42-51. 